\title{
The role of sex hormones and social determinants in assessment of facial attractiveness
}

\author{
Passakova $\mathrm{N}^{1}$, Celec $\mathrm{P}^{1,2}$, Gardlik $\mathrm{R}^{1,2}$ \\ Institute of Pathophysiology, Faculty of Medicine, Comenius University, Bratislava, Slovakia. \\ romangardlik@gmail.com
}

\section{ABSTRACT}

OBJECTIVES: The current study is focused on assessing the factors of attractiveness of opposite-sex individuals based on evaluating photographs of their faces.

BACKGROUND: When assessing the attractiveness, factors of both, the assessed individual and the assessor play a role. The relationship of the preference for partners based on their physical appearance with the markers of prenatal testosterone is not fully understood.

METHODS: Sex hormone levels were measured in saliva, while age, social status, income and occupation were recorded. A total of 30 women and 35 men were enrolled.

RESULTS: The identified factors determining the attractiveness of menare their age and prenatal testosterone level (second-to-fourth digit ratio-2D:4D). The attractiveness of men is more influenced by the factors of evaluating women, namely the rating assigned to the men positively correlates with age, $2 \mathrm{D}: 4 \mathrm{D}$, and salivary estradiol of the evaluating women. The attractiveness of women correlated negatively with age and positively with prenatal exposure to androgens (2D:4D). The women with lower estradiol were rated higher by men who themselves had low estradiol levels. The attractiveness did not correlate with current testosterone.

CONCLUSION: This study contributes to the knowledge on the role of sex hormones in human sexuality and partner choice. Further studies should include genetic factors of testosterone metabolism. (Tab. 4, Ref. 23). Text in PDF www.elis.sk.

KEY WORDS: facial attractiveness, second-to-fourth digit ratio, 2D:4D, testosterone, estradiol.

\begin{abstract}
Abbreviations: 2D:4D - second-to-fourth digit ratio, GLM - general linear model, WHR - waist-to-hip ratio
\end{abstract}

\section{Introduction}

Physical attractiveness is defined as the perception of physical characteristics of an individual that evokes pleasure or desire. The assessment of attractiveness of physical characteristics is complex and shows evident interindividual variations. The relationship between the preference for partner based on physical signs and markers of prenatal testosterone levels is still not fully understood. According to a meta-analysis, the correlation between second-to-fourth digit ratio (2D:4D) as a predictor of prenatal levels of testosterone and men's facial attractiveness was not

${ }^{1}$ Institute of Pathophysiology, Faculty of Medicine, Comenius University, Bratislava, Slovakia, and ${ }^{2}$ Institute of Molecular Biomedicine, Faculty of Medicine, Comenius University, Bratislava, Slovakia

Address for correspondence: R. Gardlik, MD, PhD, Institute of Molecular Biomedicine, Faculty of Medicine, Comenius University, Spitalska 24, SK-813 72 Bratislava, Slovakia.

Phone: +421.2.90119 296, Fax: +421.2.90119 631

Acknowledgement: This study was supported by the grant of The Ministry of Education of the Slovak Republic [VEGA 1/0204/17]. significant (1, 2). Unknown is also the correlation between the attractiveness and current levels of sex hormones. According to available publications, the testosterone-to-estradiol ratio and low testosterone levels were positively associated with women's facial attractiveness (3). Others have found that the interaction of progesterone and estradiol adversely affect the women's attractiveness as judged by men (4). It was also found that the faces of women, but not those of men, with higher testosterone levels were considered physically more attractive. In addition, a higher estradiol-to-progesterone ratio was positively correlated with women's facial attractiveness $(4,5)$. However, recent analyses revealed no evidence that women with more attractive faces and waist-to-hip ratio have higher levels of estradiol or progesterone (6). In addition, men's current testosterone levels did not correlate with their attractiveness when rated by women upon inspecting the men's photographs but did correlate with women's physiological arousal (pupil diameter). Thus, self-rated preferences may not provide a straightforward and direct assessment of sexual attraction. The assessment of objective sexual attraction might provide more reliable and consistent findings (7).

When assessing the attractiveness, the factors of both the assessed individual and assessor play a role. Testosterone levels in men have no influence on the assessment of attractiveness as judged by women, but men with lower testosterone levels are more 
$443-448$

confident with their selections (8). The evaluation of women's attractiveness as judged by men was not affected by the current levels of testosterone in men (9). Men's preference for more feminine faces in women decreases with age, being highest among men in their 30s. These differences in preference potentially reflect the age-related decline in testosterone levels (10). In women, variations were found in the assessment of men's attractiveness during distinct phases of the menstrual cycle. Some studies confirm the role of women's current sex hormone levels in their assessment of men's attractiveness (11). The ovulatory shift hypothesis proposes that women's preferences for masculine traits reach their peak at the periovulatory period of the menstrual cycle. Consistent with this hypothesis, the increase in estradiol predicted an increase in women's preferences for more masculine faces in men, while high levels of progesterone predicted an increase in women's preferences for more feminine faces in men (12). Women's preference for men with high testosterone levels was changing with the level of estradiol during the cycle. Higher estradiol level correlated with a preference for androgen-dependent traits in men (13). On the other hand, recent studies showed that women's preferences for men's facial masculinity did not change over the menstrual cycle and were not associated with levels of estradiol, progesterone or luteinizing hormone $(14,15)$. Interestingly, based on the assessment of photographs, single men's faces were rated by women as more masculine and thus more attractive than those of partnered men (16). This is in line with previous findings that single males have higher testosterone levels than partnered males and that higher testosterone levels are associated with higher attractiveness.

It is believed that physical attractiveness influences several key aspects in human life. People who are perceived as more attractive have better school results, better jobs, higher wages, and higher chance of getting married. Women tend to select a longterm partner with certain genetic and health characteristics, and features indicating good access to resources. Although males often attain status and wealth later in life, their potential for the future can be assumed earlier. The resource-holding potential may have various determinants such as family background, education, profession, and intelligence. Women take often these attributes into account when choosing their ideal partner. It has been shown that women who are more attractive have higher probability to marry a partner with a higher social status (17). Subjects of the study were assessed as more attractive when they lived in more favorable socio-economic conditions during their childhood (18).

The current work focused on assessing the attractiveness of opposite-sex individuals based on evaluating their photographs. Levels of sex hormones were measured in saliva, while factors influencing the assessment of attractiveness were recorded, including age, social status, marital status and duration of relationship, monthly expenditure, and occupation.

\section{Materials and methods}

\section{Study design}

Two separate studies have been conducted. Both studies were divided into two rounds. In the first round, the participants pro- vided basic personal information on their socioeconomic status and life partner, and provided standardized photographs of their face and right-hand palm. In the second round of Study I blood and saliva samples were collected for testosterone levels measurement. Female participants provided their samples on 21st day of their menstrual cycle. In the second round of Study II, participants were mailed a sterile tube for saliva collection. Using the facial photographs, the participants rated the visual attractiveness of each other on a scale from $0-10,0$ being the least attractive and 10 the most attractive.

\section{Study participants}

Twelve women and fourteen men were enrolled in Study I. Sixteen women and twenty-one men were enrolled in Study II. The average age of men in Study I was 20.8 years (between 20 and 22). The average age of men in Study II was 26.1 years (between 22 and 33). The average age of women was 26.3 years (between 20 and 27) in Study I and 27.4 years (between 19.3 and 44.2) in Study II. One of the women in Study II was married.

\section{Measurement of hormone levels}

Testosterone was measured using DRG Testosterone ELISA Kit (DRG Diagnostics, Marburg, Germany) according to the manufacturer's instructions. Similarly, estradiol was measured using DRG Estradiol ELISA Kit (DRG Diagnostics, Marburg, Germany) according to the manufacturer's instructions.

\section{Measurement of second-to-fourth digit ratio (2D:4D)}

The lengths of second and fourth fingers (2D and 4D) of the right hand was measured on palm scans using software Gimp 2.8.0 and the 2D:4D ratio was calculated.

\section{Data analysis}

Data were analyzed using XLStatistics 20 (Microsoft, Redmond, Washington, USA) and SPSS (IBM, Armonk, New York, USA). To analyze the results and search for correlations between different factors, we have created all possible combinations of man-woman pairs from the whole set of subjects. The relationship between the factors was studied by correlation and linear regression analysis. The general linear model (GLM) was used to examine the dependency of one or more interval variables on one or more independent intervals and/or nominal variables. GLM explains the dependence of two variables in view of all the data collected. The correlation model is used to detect single, paired dependent phenomena in isolation.

\section{Results}

\section{Study I}

In Study I, the influence of multiple factors on the assessment of attractiveness of the opposite-sex individuals was investigated. It was found that among all, the only male factor, which determines the rate of women's attraction to men is the age of the latter. The study did not confirm our assumption of correlation of men's attractiveness as evaluated by women with the level of prenatal male 
Tab. 1. Evaluation of men's attractiveness as assessed by women.

\begin{tabular}{|c|c|c|c|}
\hline Factor & Ranking change & Standardized beta coefficient & Significance (p value) \\
\hline Men's age & $0 . .860$ & $0 . .268$ & $<0.001$ \\
\hline The length of women's second finger & 0.301 & 0.375 & 0.005 \\
\hline Length of women's partnership & 0.732 & 0.919 & $<0.001$ \\
\hline Women's monthly expenses & -0.016 & -0.937 & $<0.001$ \\
\hline Level of women's salivary testosterone & -0.008 & -0.348 & 0.001 \\
\hline \multicolumn{4}{|l|}{ After normalization } \\
\hline Man’s age & 0.224 & 0.277 & 0.001 \\
\hline
\end{tabular}

Tab. 2. Evaluation of the attractiveness of men as assessed by women.

\begin{tabular}{|c|c|c|c|}
\hline Factor & Ranking change & Standardized beta coefficient & Significance (p value) \\
\hline Level of women's salivary testosterone & -0.005 & -0.299 & $<0.001$ \\
\hline Length of men’s partnership & 0.576 & 0.534 & $<0.001$ \\
\hline Men’s monthly expenses & -0.015 & -0.457 & $<0.001$ \\
\hline \multicolumn{4}{|l|}{ After normalization } \\
\hline Level of women's salivary testosterone & -0.001 & -0.334 & $<0.001$ \\
\hline
\end{tabular}

The table shows the change in the attractiveness score based on the change in factor after normalization by one unit.

Tab. 3. General linear model of Study II.

\begin{tabular}{|c|c|c|c|c|c|c|}
\hline Source & & $\begin{array}{c}\text { Type III Sum of } \\
\text { Squares } \\
\end{array}$ & df & Mean Square & F & Sig \\
\hline Corrected Model & $\begin{array}{l}\text { XYEVALXX } \\
\text { XXEVALXY }\end{array}$ & $\begin{array}{l}670.792 \mathrm{a} \\
397.651 \mathrm{~b}\end{array}$ & $\begin{array}{l}8 \\
8\end{array}$ & $\begin{array}{l}83.849 \\
49.706\end{array}$ & $\begin{array}{l}18.871 \\
10.613\end{array}$ & $\begin{array}{l}<\mathbf{0 . 0 0 1} \\
<\mathbf{0 . 0 0 1}\end{array}$ \\
\hline XYTST & $\begin{array}{l}\text { XYEVALXX } \\
\text { XXEVALXY }\end{array}$ & $\begin{array}{l}5.566 \\
6.619 \\
\end{array}$ & $\begin{array}{l}1 \\
1 \\
\end{array}$ & $\begin{array}{l}5.566 \\
6.619 \\
\end{array}$ & $\begin{array}{l}1.253 \\
1.413 \\
\end{array}$ & $\begin{array}{l}0.264 \\
0.235 \\
\end{array}$ \\
\hline XXTST & $\begin{array}{l}\text { XYEVALXX } \\
\text { XXEVALXY }\end{array}$ & \begin{tabular}{|l}
.681 \\
2.321 \\
\end{tabular} & $\begin{array}{l}1 \\
1 \\
\end{array}$ & $\begin{array}{l}0.681 \\
2.321 \\
\end{array}$ & $\begin{array}{l}0.153 \\
0.496 \\
\end{array}$ & $\begin{array}{l}0.696 \\
0.482 \\
\end{array}$ \\
\hline XYEST & $\begin{array}{l}\text { XYEVALXX } \\
\text { XXEVALXY }\end{array}$ & $\begin{array}{c}27.492 \\
2.368 \\
\end{array}$ & $\begin{array}{l}1 \\
1 \\
\end{array}$ & $\begin{array}{l}27.492 \\
2.368 \\
\end{array}$ & $\begin{array}{l}6.187 \\
0.506 \\
\end{array}$ & \begin{tabular}{l|l|}
$\mathbf{0 . 0 1 3}$ \\
0.478 \\
\end{tabular} \\
\hline XXEST & $\begin{array}{l}\text { XYEVALXX } \\
\text { XXEVALXY } \\
\end{array}$ & $\begin{array}{c}277.419 \\
73.844 \\
\end{array}$ & $\begin{array}{l}1 \\
1 \\
\end{array}$ & $\begin{array}{c}277.419 \\
73.844 \\
\end{array}$ & $\begin{array}{l}62.435 \\
15.767 \\
\end{array}$ & $\begin{array}{l}<0.001 \\
<0.001 \\
\end{array}$ \\
\hline$\overline{\mathrm{XYAGE}}$ & $\begin{array}{l}\text { XYEVALXX } \\
\text { XXEVALXY } \\
\end{array}$ & \begin{tabular}{|c|}
.172 \\
28.852 \\
\end{tabular} & $\begin{array}{l}1 \\
1 \\
\end{array}$ & $\begin{array}{c}0.172 \\
28.852 \\
\end{array}$ & $\begin{array}{l}0.039 \\
6.161 \\
\end{array}$ & $\begin{array}{l}0.844 \\
\mathbf{0 . 0 1 4} \\
\end{array}$ \\
\hline$\overline{\mathrm{XXAGE}}$ & $\begin{array}{l}\text { XYEVALXX } \\
\text { XXEVALXY }\end{array}$ & $\begin{array}{l}149.854 \\
137.545 \\
\end{array}$ & $\begin{array}{l}1 \\
1 \\
\end{array}$ & $\begin{array}{l}149.854 \\
137.545 \\
\end{array}$ & $\begin{array}{l}33.726 \\
29.368 \\
\end{array}$ & $\begin{array}{l}<0.001 \\
<0.001 \\
\end{array}$ \\
\hline XY2D4D & $\begin{array}{l}\text { XYEVALXX } \\
\text { XXEVALXY } \\
\end{array}$ & $\begin{array}{c}1.055 \\
11.949 \\
\end{array}$ & $\begin{array}{l}1 \\
1 \\
\end{array}$ & $\begin{array}{c}1.055 \\
11.949 \\
\end{array}$ & $\begin{array}{l}0.237 \\
2.551 \\
\end{array}$ & $\begin{array}{l}0.626 \\
0.111 \\
\end{array}$ \\
\hline XX2D4D & $\begin{array}{l}\text { XYEVALXX } \\
\text { XXEVALXY } \\
\end{array}$ & $\begin{array}{l}159.841 \\
111.442 \\
\end{array}$ & $\begin{array}{l}1 \\
1 \\
\end{array}$ & $\begin{array}{l}159.841 \\
111.442 \\
\end{array}$ & $\begin{array}{l}35.973 \\
23.795 \\
\end{array}$ & $\begin{array}{l}<0.001 \\
<0.001 \\
\end{array}$ \\
\hline
\end{tabular}

The columns show factors of evaluation. Significant results are highlighted. XYEVALXX = evaluation of women by men, XXEVALXY = evaluation of men by women, XYTEST = men's salivary testosterone level, XXTEST = women's salivary testosterone level, XYEST = men's salivary estradiol level, XXEST = women's salivary estradiol level, XYAGE = men's age, XXAGE = women's age, XY2D:4D = 2nd-to-4th digit ratio in men, XX2D:4D = 2nd-to-4th digit ratio in women

testosterone (2D:4D ratio) or actual level of testosterone. Men’s attractiveness as assessed by women depends more on factors of the latter. It was found that higher 2D:4D ratio and longer partnership of women have positive influence on the evaluation of men's attractiveness. On the other hand, higher monthly expenditure and higher levels of salivary testosterone in women negatively correlates with their assessment of men. After normalization, the only significant factor to be found was that of the age of evaluated men. Older men received higher score then younger ones. Table 1 shows the changes in evaluating the male attractiveness based on the change in monitoring factors by one unit.
The attractiveness of women as evaluated by men was found to be significantly dependent on the factor of the level of salivary testosterone in women. Higher levels of salivary testosterone in women have a negative impact on their attractiveness as judged by men, even after normalization. Higher monthly expenditure of men correlated with a downward shift in the scores they assigned to women's attractiveness. On the other hand, longer partnership of men correlated with an upward shift in the scores assigned by them to the attractiveness of women. The results are summarized in Table 2. After normalization, the only factor to be found significant was that of salivary testosterone in evaluated women. 
Study II

Highly rated were women with low levels of estradiol, but only when the evaluating man himself had low levels of estradiol. Higher scores were given to younger women. Low 2D:4D ratios (higher prenatal exposure to androgenic hormones) of women correlated with higher scores given by men.

The rate of male attractiveness was determined by characteristics of the evaluating women rather than those of evaluated men. Men's attractiveness positively correlated with age, estradiol levels, and 2D:4D ratio of the evaluating women (Tab. 3). Men with lower 2D:4D ratio (high prenatal exposure to androgens) and younger men were considered more attractive.

A considerable influence of some factors on the attractiveness score was found in the correlation model, but not in GLM. The correlation model examines the dependency of two variables in isolation, while GLM examines factors generally in the view of all data (Tab. 4).

\section{Comparison of both studies}

In both studies, the men's attractiveness seems to be predominantly influenced by factors of the evaluating women rather than those of evaluated men. In Study II, younger men were rated as more attractive, whereas in Study I, it was older men who were considered more attractive. This difference may be caused by different sets of subjects. Study I involved men in the age range of 20-22 years, whereas Study II involved those in the age range of 22.8-36.1 years. The age of women was also a significant factor affecting the rate of attraction of women to men. In general, older women gave higher scores to men. In study I however, this finding was not significant. Again, this might be caused by the fact that there was a difference between the age range of women in Study II (19-44 years) and Study I (20-27 years). Never- theless, women's factors, rather than those of men, seem to represent stronger determinants of men's attractiveness. This relationship is maintained in both studies. In Study I, the factors that significantly influenced the evaluation of women by men included men's age, women's 2D:4D ratio, length of relationship, monthly expenditure and salivary testosterone. This finding, however, was not confirmed in Study II.

\section{Discussion}

The current study aimed to evaluate the association between the assessment of facial attractiveness (using photographs) and biological (levels of sex hormones) as well as social factors that might influence this assessment. Lower 2D:4D ratio, which correlates with higher prenatal exposure to androgens, had a positive influence on rating assigned to women by men. The correlation between 2D:4D ratio and attractiveness related to body odors was previously described by others authors (19). Men with more masculine, lower 2D:4D ratio were considered more attractive. A meta-analysis showed no correlation between 2D:4D ratio and men's facial attractiveness, but the association cannot be ruled out $(1,2)$. Although the correlation between 2D:4D ratio and current attractiveness is not significant, it does not necessarily have to mean that the actual level of prenatal testosterone has no effect on male attractiveness.

The present study did not confirm any association between current testosterone levels and attractiveness. However, our study did not take into consideration the secondary sexual characteristics given by testosterone levels, such as body hair. According to other authors, the amount of body hair correlated negatively with the attractiveness of men (20). Body hair is related to circulating androgens and is regarded as one of secondary sex characteristics. Subjects in the study by Dixson et al. were rated using naked body photographs. As opposed to the latter, the attractiveness in this study was assessed by face photographs.

Current knowledge infers that higher levels of sex hormones increase the subject's attractiveness (13). Study demonstrating the differences between hormonal predictors of preference dependent on testosterone and masculine facial initiatives found that estradiol or testosterone levels change insignificantly the foreseen change in preferences for masculine facial features. These results are not in contradiction with our findings.

The authors undertaking the research on 60 Latvian men have found a relationship between facial and vocal attractiveness and masculinity, height, testosterone levels and antibodies (20). According to our study, women's preference for men's facial attractiveness correlates with circulating levels of testosterone and antibodies. Attractive facial characteristics are a measure of good immune response and represent a factor for natural selection, which means a higher rate of successful fights with infections, and higher average age of survival of a subject and his offspring. Interestingly, based on the assessment of photographs, single men's faces were rated by women as more masculine and thus more attractive than those of partnered men (16). This is in line with previous findings, namely that single males have higher testosterone levels than 
partnered males and that higher testosterone levels are associated with higher attractiveness.

During the menstrual cycle, estradiol and progesterone levels and women's preference for men undergo changes (21). During ovulation women prefer men with higher levels of androgens. We did not find any correlation between the attractiveness or assessment of attractiveness and the phase of the cycle in Study I. Furthermore, we assume that nowadays, majority of women at fertile age use hormonal contraceptives. During the menstrual cycle, women's preferences for masculinity in male faces, voices and behavior are subjected to changes which are the strongest in periovulatory period (9). On the other hand, recent studies showed that women's preferences for men's facial masculinity did not change over the menstrual cycle and were not associated with levels of estradiol, progesterone or luteinizing hormone $(14,15)$.

Women's age was a factor that significantly influenced the rating of men's attractiveness as assessed by women. Younger women gave higher scores. Other authors found a correlation between men's age and men's attractiveness. When assessed by women, the attractiveness of men's faces decreased with age of the assessed men (10). The most attractive were the men in their 30s while least attractive were those in their 70s.

There are only few works that examined the relationship between sex hormone levels and face attractiveness, and thus the empirical evidence of this relationship is still missing. It is possible that subjects' current levels of sex hormones are not directly related to their attractiveness $(6,7)$. However, sex hormones influence the attractiveness through the development of secondary sexual characteristics such as body composition and body hair at puberty. Interesting results were found in a study by Ferdenzi et al, where more attractive were seen the women with low testosterone levels and low testosterone-to-estradiol ratio (22). The latter low ratio seemed to be in a stronger correlation with attractiveness than isolated low testosterone levels. Interestingly, the absolute current women's estradiol levels were in no association with their own attractiveness. In Study I, we found a significant association between increasing levels of salivary testosterone in women and negative assessment of their attractiveness. The same conclusions were pronounced, namely that as more attractive are rated the women with lower current levels of testosterone. In Study II, a preference for women with low levels of estradiol was found, but only if the latter hormone level of the assessing man was low as well. In the above-mentioned study, the authors did not examine the hormone levels of the evaluating men. A study on budgerigars showed that an experimental increase in female testosterone levels did not affect male preference in choosing the partner (23).

Some of our results were not expected. A correlation was found between current levels of men's testosterone and 2D:4D ratio. Also, the correlation between age and 2D:4D ratio in men as well as that between age and estradiol level in women were found. It is obvious that there is a sex difference in the evaluation of attractiveness. The attractiveness of men is more dependent on the factors of evaluating women.

One of the major limitations of our study was a small number of participants. Further, our study was purely a correlation study, and therefore it is hard to explain the causal relationships. It is not clear why the current level of sex hormones is associated with the assessment of attractiveness of the opposite sex.

The hypothesis that attractiveness and assessment of attractiveness in the opposite sex correlates with current testosterone levels was not confirmed. On the other hand, a correlation was found between the current estradiol levels and attractiveness. The results are interesting and supplement the previously published literature. Facial attractiveness is demonstrated by several authors as an important determinant of partner selection and quality of the gene pool. Nevertheless, future studies might include additional factors such as progesterone levels, surface of the face, skin color or texture, symmetry, masculinity or femininity of facial characteristics or BMI. This study contributes to the knowledge on the role of sex hormones in human sexuality and choice of partner. Overall, this knowledge can have implications for people's attitudes and behavior, aesthetics, but also lifestyle and human health.

\section{References}

1. Neave N, S Laing, B Fink, JT Manning. Second to fourth digit ratio, testosterone and perceived male dominance. Proc Biol Sci 2003; 270 (1529): 2167-2172.

2. Honekopp J. Digit ratio (2D:4D) and male facial attractiveness: new data and a meta-analysis. Evol Psychol 2013; 11 (5): 944-952.

3. Probst F, C Bobst, JS Lobmaier. Testosterone-to-oestradiol ratio is associated with female facial attractiveness. Q J Exp Psychol (Hove) 2016; 69 (1): 89-99.

4. Puts DA, DH Bailey, RA Cardenas et al. Women's attractiveness changes with estradiol and progesterone across the ovulatory cycle. Horm Behav 2013; 63 (1): 13-19.

5. Wang H, AC Hahn, CI Fisher, LM DeBruine, BC Jones. Women's hormone levels modulate the motivational salience of facial attractiveness and sexual dimorphism. Psychoneuroendocrinology 2014; 50: 246-251.

6. Jones BC, AC Hahn, CI Fisher et al. No compelling evidence that more physically attractive young adult women have higher estradiol or progesterone. Psychoneuroendocrinology 2018; 98: 1-5.

7. Hagerman S, Z Woolard, K Anderson, BW Tatler, FR Moore. Women's self-rated attraction to male faces does not correspond with physiological arousal. Sci Rep 2017; 7 (1): 13564.

8. Bobst C, JS Lobmaier. Is preference for ovulatory female's faces associated with men's testosterone levels? Horm Behav 2014; 66 (3): 487-492.

9. Welling LL, BC Jones, LM DeBruine et al. Men report stronger attraction to femininity in women's faces when their testosterone levels are high. Horm Behav 2008; 54 (5): 703-708.

10. Marcinkowska UM, BJ Dixson, MV Kozlov, K Prasai, MJ Rantala. Men's Preferences for Female Facial Femininity Decline With Age. J Gerontol B Psychol Sci Soc Sci 2017; 72 (1): 180-186.

11. Hernandez-Lopez L, DM Garcia-Granados, R Chavira-Ramirez, R Mondragon-Ceballos. Testosterone, the progesterone/estradiol ratio, and female ratings of masculine facial fluctuating asymmetry for a longterm relationship. Physiol Behav 2017; 175: 66-71. 
$443-448$

12. Dixson BJW, KR Blake, TF Denson et al. The role of mating context and fecundability in women's preferences for men's facial masculinity and beardedness. Psychoneuroendocrinology 2018; 93: 90-102.

13. Roney JR, ZL Simmons, PB Gray. Changes in estradiol predict within-women shifts in attraction to facial cues of men's testosterone. Psychoneuroendocrinology 2011; 36 (5): 742-749.

14. Dixson BJW, AJ Lee, KR Blake, G Jasienska, UM Marcinkowska. Women's preferences for men's beards show no relation to their ovarian cycle phase and sex hormone levels. Horm Behav 2018; 97: 137-144.

15. Marcinkowska UM, A Galbarczyk, G Jasienska. La donna e mobile? Lack of cyclical shifts in facial symmetry, and facial and body masculinity preferences-A hormone based study. Psychoneuroendocrinology 2018; 88: 47-53.

16. Mahmut MK, RJ Stevenson. Do Single Men Smell and Look Different to Partnered Men? Front Psychol 2019; 10: 261.

17. Harper B. Beauty, stature and the labour market: A British cohort study. Oxford B Econ Stat 2000; 62 (s1): 771-800.
18. Benzeval M, MJ Green, S Macintyre. Does perceived physical attractiveness in adolescence predict better socioeconomic position in adulthood? Evidence from 20 years of follow up in a population cohort study. PLoS One 2013; 8 (5): e63975.

19. Roberts SC, A Kralevich, C Ferdenzi et al. Body odor quality predicts behavioral attractiveness in humans. Arch Sex Behav 2011; 40 (6): 1111-1117.

20. Dixson BJ, AF Dixson, PJ Bishop, A Parish. Human physique and sexual attractiveness in men and women: a New Zealand-U.S. comparative study. Arch Sex Behav 2010; 39 (3): 798-806.

21. Jovic T, A Pavlic, S Varga, D Kovacevic Pavicic, M Slaj, S Spalj. Perception of facial profiles: influence of female sex hormones and personality traits. Orthod Craniofac Res 2016; 19 (4): 209-215.

22. Ferdenzi C, JF Lemaitre, JD Leongomez, SC Roberts. Digit ratio (2D:4D) predicts facial, but not voice or body odour, attractiveness in men. Proc Biol Sci 2011; 278 (1724): 3551-3557.

23. Durante KM, NP Li. Oestradiol level and opportunistic mating in women. Biol Lett 2009; 5 (2): 179-182. 